\title{
"Lutembacher's Syndrome" - A Case Report
}

Hatem Saeed $^{1}$, A. Ahminedache ${ }^{1}$, Dinia Mohamed ${ }^{1}$, El Boussaadani Badre ${ }^{2 *}$, N. Fellat ${ }^{1}$

${ }^{1}$ Departement of Cardiology A, IBN Sina Hopital, Rabat, Morocco

${ }^{2}$ Department of Cardiology B, IBN Sina University Medical center Rabat, Morocco

DOI: $10.36347 /$ sjmcr.2020.v08i03.012

| Received: 28.02.2020 | Accepted: 06.03.2020 | Published: 10.03.2020

*Corresponding author: Dr. El Boussaadani Badre

Abstract

Lutembacher's syndrome is one of the complex heart diseases and its incidence is very rare. It comprises Atrial Septal Defect (ASD) Secundum with Mitral stenosis (MS). Iinter-atrial septum develops from two sources-septum primium and septum secundum. If defect in the formation of septum primium-it forms ASD (Primium) and If defect in the formation of septum secundum it forms ASD (secundum). Mitral stenosis is an acquired heart disease developes due to recurrent attack of Rheumatic carditis. So, for the development of Lutembacher's syndrome defect in the formation of septum secundum and recurrent Rheumatic carditis are required. We report the case of à 33 years old female admitted for dyspnea, echocardiography was performed and had objective Lutemvacher's syndrome.

Keywords: Lutembacher's syndrome, Atrial septal defect, mitral stenosis.

Copyright @ 2020: This is an open-access article distributed under the terms of the Creative Commons Attribution license which permits unrestricted use, distribution, and reproduction in any medium for non-commercial use (NonCommercial, or CC-BY-NC) provided the original author and source are credited.

\section{INTRODUCTION}

Heart disease comprises - congenital heart disease and acquired heart disease. There are many heart diseases which are very complex form, that is combination of congenital and acquired in origin. Lutembacher's syndrome is one of the complex heart diseases and its incidence is very rare. It comprises Atrial Septal Defect (ASD) Secundum with Mitral stenosis (MS). Iinter-atrial septum develops from two sources-septum primium and septum secundum. If defect in the formation of septum primium-it forms ASD (Primium) and If defect in the formation of septum secundum it forms ASD (secundum). Mitral stenosis is an acquired heart disease developes due to recurrent attack of Rheumatic carditis. So, for the development of Lutembacher's syndrome defect in the formation of septum secundum and recurrent Rheumatic carditis are required.

\section{Case Report}

33-year-old female patient with ATCD: Untreated recurrent angina history of the disease: 4 years Dyspnea of progressive aggravation + asthenia. Erythrosis of the cheekbones TA $=120 / 70 \mathrm{~mm} \mathrm{Hg}, \mathrm{Fc}$ $=80 \mathrm{bpm}$, Irregular rhythm. At the mitral hearth: Diastolic rolling, radiance B1. At the pulmonary focus: B2 burst, duplication of heart sounds in exhalation. Electrocardiogram objective atrial fibrillation at 80 beats per minute. Objective echocardiography: Reformed mitral valve thickened, short and thick valvular apparatus; $\mathrm{SM}=0.75 \mathrm{~cm}^{2}, \mathrm{Gd}$ mean $=9$ $\mathrm{mmHg}$, minimal IM. Thin tricuspid valve, large IT at $3.38 \mathrm{~m} / \mathrm{s}, 34 \mathrm{~mm}$ ring. Cavities right dilated (DTDVD $=52 \mathrm{~mm}$ ) systolic function conserved. PAPS $=45+15$ $=60 \mathrm{mmHg}$. Dilated pulmonary pathway CIA with ostium secondum has $18 \mathrm{~mm}$ and shunt left right. OG dilated LV of normal size and function $(\mathrm{FE}=63 \%)$ without segmental kinetic disorders, the patient has benefitted from mitral valve replacement and closure of CIA and tricuspid annuloplasty with good evaluation. 

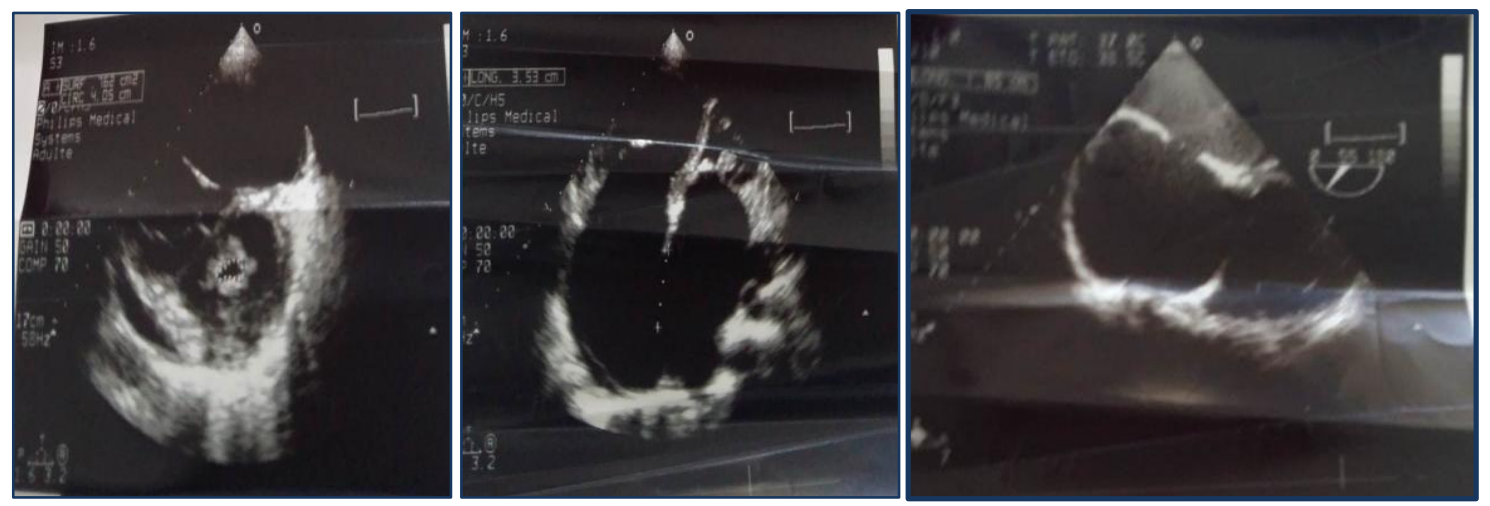

\section{DISCUSSION}

The definition of Lutembacher syndrome has undergone many changes. This syndrome brings together a congenital defect of the inter-auricular septum which causes inter-auricular communication type ostium secondum (ASD) and acquired mitral stenosis most often of rheumatic origin.Lutembacher's syndrome comprises Mitral Stenosis with ASD. Its incidence is very rare. In one study published in American Heart Journal in 1997, it is found that the incidence of Lutembacher's syndrome is $0.001 / 10,00000$. Early diagnosis and surgical treatment bears a good prognostic value. If patient is diagnosed at late stage, pulmonary hypertension and heart failure develops and the prognosis is bad. If the patient is diagnosed earlier before the development of pulmonary hypertension and heart failure - ASD closure with Mitral valve replacement bears a good prognosis and prolongs survival.

Hemodynamics depends on the size of the septal defect and the severity of the mitral stenosis as well as the compliance of the right ventricle: Pressure of the left atrium decreases at the expense of the right atrium (ASD) Mitral stenosis increases the right left shunt; this avoids pulmonary congestion but exposes in the long term to pulmonary hypertension $(\mathrm{PH})$ which will later become irreversible.

The treatment in Lutembacher syndrome is mainly surgical. But with the introduction of the balloon percutaneous mitral valve and closure of the ASD patients can now be treated safely and effectively by percutaneous means when the anatomy of the interauricular septum and the Mitral valve morphology are appropriate [1].

However, the procedure is not a simple combination of two simple procedures, Septal defect simplifies the mitral valve, the size of the communication intervenes in the stability of the catheter, a large space will make the balloon very mobile and will not allow its stabilization within the mitral stenosis. Added to this is the possibility of a misalignment of the umbrella or its embolization [2].
In our case the septal defect was very large to prepare for a percutaneous closure and the machine under the mitral valve was redesigned and thickened not allowing balloon expansion, then the repair had to be surgical. It is noted that in the presence of significant pulmonary hypertension the closure of the CIA could cause right ventricular dysfunction that could be fatal, Indeed the increase in pressure in the right atrium tends to reverse the direction of the shunt and thus contributes to decrease the level of pulmonary hypertension [3].

When the diagnosis of Lutembacher syndrome is made late in the severe $\mathrm{PH}$ stage, a replacement of the mitral valve and an incomplete closure of the ASD by leaving a small inter-atrial communication would have good results and would prolong patient survival. However the long-term evolution of lung disease remains uncertain.

\section{Conclusion}

Lutembacher's syndrome is a rare, complex, congenital heart diseases. Early diagnosis and operative treatment has a good prognostic value but late diagnosis and development of heart failure bears bad prognosis. Most of the patients die subsequently due to heart failure, cardiac arrhythmias and thrombo-embolic cerebro vascular diseases. Early diagnosis and management can reduce morbidity and mortality.

\section{REFERENCE}

1. Cheng TO. Coexistent atrial septal defect and mitral stenosis (Lutembacher syndrome): An ideal combination for percutaneous treatment. Catheterization and Cardiovascular Interventions. 1999 Oct;48(2):205-6.

2. Vadivelu R, Chakraborty S, Bagga S. Transcatheter therapy for Lutembacher's syndrome: The road less travelled. Annals of pediatric cardiology. 2014 Jan;7(1):37.

3. Talwar S, Choudhary SK, Saxena A, Kothari SS, Juneja R, Airan B. Unidirectional valved patches for closure of septal defects in patients with severe pulmonary hypertension. Annals of pediatric cardiology. $2008 \mathrm{Jul} ; 1(2): 114-119$. 